\title{
Unité de doctrine
}

\author{
B. Gurtner
}

\section{Akt}

Sie fragt den Chefarzt: «Wenn wir Glück haben, noch viele Jahre.» Sie bestürmt die Oberärztin: «Wenn Sie Pech haben, nur noch wenige Monate.» Sie erkundigt sich beim Onkologen: «Nach neueren Studien haben Sie eine 5-JahreÜberlebenschance von 42\%.» Sie bittet den Spitalpfarrer um seine Meinung: «Wer weiss? Das liegt in Gottes Hand.» Sie fragt ihre beste Freundin: «Du wirst das schon durchstehen. Ich gebe dir noch die Adresse des Krebsspezialisten, der Susi geheilt hat.»

\section{Hat man nach der Operation viele Schmerzen?}

Arzt 1: Das werden wir heute abend in Ruhe besprechen, ich muss jetzt zum Rapport.

Arzt 2: Ich bin erst seit Anfang Monat hier, fragen Sie bitte den Oberarzt.

Arzt 3: Das ist von Patient zu Patient sehr verschieden ... (wird weggerufen durch Piepser).

Arzt 4: Machen Sie sich keine unnützen Sorgen, das wird nicht weiter schlimm (setzt Stethoskop auf), atmen Sie bitte ganz tief durch!

Pflegefachfrau 1: Das kann Ihnen der Chirurg oder Anästhesist professioneller erklären.

Pflegefachfrau 2: Man wird Ihnen genügend Mittel verabreichen. 'tschuldigung, ich muss jetzt rasch ...

Pflegefachfrau 3: Die Schmerzen sind meistens nicht sehr stark und gehen nach zwei bis drei Tagen vorbei. Sie werden uns sagen, wieviel Schmerzmittel Sie brauchen. Aufstehen dürfen Sie schon am Abend des Operationstages, dann kommt meistens auch die Infusion weg. Am Mittwoch können Sie wieder essen.

Wann kann ich wieder baden oder wenigstens duschen?

Erste Auskunft: Etwa nach einer Woche.

Zweite Auskunft: Das kommt ganz darauf an ... Dritte Auskunft: Schon sofort wieder, wir kleben Ihnen eine wasserdichte Folie auf die Wunde.

\section{Akt}

Wann darf ich nach Hause? Wann kann ich wieder arbeiten?

Assistenzarzt: Wenn Sie zwei Tage fieberfrei sind, lassen wir sie nach Hause. Ich gebe Ihnen dann noch ein Zeugnis für 10 Tage Arbeitsunfähigkeit.

Oberärztin: Wir wollen nichts überstürzen, bleiben Sie noch bis nächsten Samstag hier. Falls Sie sich ordentlich fühlen, können Sie ab übernächsten Montag wieder 50\% arbeiten, das weitere bestimmt der Hausarzt.

Chefarzt: Ich würde Sie gerne noch länger hierbehalten. Weil wir knapp an Betten sind und genaue Vorschriften der Verwaltung haben, muss ich Sie leider bitten, schon morgen auszutreten. Die Nachbehandlung kann jetzt Ihre Hausärztin übernehmen, sie wird auch die Arbeitsunfähigkeit festlegen.

Physiotherapeutin: Ich habe Sie diese Woche noch dreimal für Atemgymnastik vorgemerkt. Was, die wollen Sie schon morgen heimschicken?

Diabetesberaterin: Übermorgen werde ich Ihnen zeigen, wie man den Blutzucker selber messen kann. Sie sind dann schon nicht mehr hier? Könnten Sie auch ambulant vorbeikommen? Das ist nicht möglich? Na dann ...

Putzfrau: Doch, du gehen schon öite aim! Is nix wahr? Mir aben sie gesaggt, du müssen aim subito ... (knallt heftig mit Besen an Bettpfosten). 